\title{
REFLEJOS LITERARIOS DE LA PROBLEMÁTICA ÁRABE MODERNA (DEL SIGLO XVIII A LA PRIMERA GUERRA MUNDIAL)
}

\section{Clara $M^{\underline{a}}$ Thomas de Antonio}

Los escritores árabes han venido reflejando en sus obras los problemas de toda índole que han sacudido a su mundo, la conflictiva evolución de su historia moderna y contemporánea. Como testigos de su época son mayoría los que han intentado mejorar su sociedad por medio de la denuncia de sus lacras, detectando los problemas y proponiendo soluciones.

La situación actual hunde sus raíces en la época del Imperio Otomano, que desde el siglo XVI dominará la mayor parte del mundo árabe; éste se irá emancipando de él entre los siglos XIX y XX, para caer en poder de las potencias occidentales, tardando décadas en lograr su independencia. Aquí vamos a exponer algunos textos relevantes de las etapas de pre-independencia, en las que aún no se han impuesto los Mandatos sobre el Oriente Medio, pero se van implantando protectorados en varios países árabes ${ }^{1}$.

\section{1.- EL SIGLO XVIII.}

En el siglo XVIII existía en las diversas provincias del Imperio Otomano una sociedad de fuertes contrastes; el control del poder estaba en manos de grupos oligárquicos que mantenían a las masas marginadas, sin que existiera una burguesía intermedia. A esto habría que añadir una situación de pre-colonización capitalista occidental, especialmente en el campo mercantil, que incidía en la política y la administración y en el incremento de las lacras sociales ${ }^{2}$.

En la rica literatura popular árabe abundan las obras de Sirra centradas en la figura de un héroe. El pueblo va a gustar de ellas porque este héroe refleja sus frustradas aspiraciones. La figura de un anti-héroe también servirá como vehículo para criticar a

\footnotetext{
${ }^{1}$ Las notas a pie de página siguen el sistema "autor, fecha: página", y se refieren a la bibliografía incluida al final del trabajo.

${ }^{2}$ MZ. MONTÁVEZ, 1985: 13.
} 
cualquier autoridad despótica. Éste es el caso de algunas de las divertidas historietas de Ŷuhâa (Yehá) que con su simpática astucia logra esquivar la tiranía de cualquier sultán, pachá o cadí. He aquí un ejemplo de su opinión sobre Tamerlán:

Un día le dijo Tamerlán:

- Sabrás, oh Yehá, que todos los califas abasidas llevan un sobrenombre especial. Uno se titula: El que acepta lo que Dios depara; otro, El que confía en el Señor; otro, El que se refugia en el Señor, y análogamente los demás. Dime; si yo fuera uno de ellos, ¿qué sobrenombre debería adoptar?

Sin vacilar, le contestó Yehá:

- Señor, sin duda os llamaríais: ¡Líbrenos Dios! ${ }^{3}$.

Sin embargo, la literatura árabe culta está totalmente anquilosada ya que se partía de la idea de que los modelos 'abbâsíes eran insuperables. Por lo tanto se limitaba a una literatura de glosas y comentarios repetitivos, manteniéndose alejada de las preocupaciones de las masas, analfabetas e ignorantes. Pero la situación de estancamiento cultural de sus instituciones va a ser denunciada ya por el egipcio Hasan al-Hị̂yâzî (m. en 1713) que criticará a los ulemas del Azhar, más preocupados por su status que por instruir con sus arcaicos métodos:

A la mezquita del Azhar le ha afligido

el Dios de la grandeza y de la vida.

Con todos esos rudos cabezotas

que ni siquiera saben saludarte.

Son auténticas rocas: ¿No poseen también

su seca e insensible pesadez?

Con sus grandes turbantes, y mangas

ensanchadas para poder mandar.

Y con noventa manuscritos, o más, debajo de los brazos ${ }^{4}$.

La necesidad de revisar el Islam, auténtico pilar de su sociedad, va a plasmarse en algunos intentos de reforma. Un ejemplo sería el wahhâbismo, movimiento riguroso y puritano liderado por Mulhammad ${ }^{\mathrm{C}} \mathrm{Albd}$ all-Wahhâh (m. en 1791) en Arabia, cuya doctrina sigue aún actuante en dicho país y fuera de él. Siguiendo las huellas de Ibn Taymîya (m. en 1328) propone un retorno a las bases primitivas del Islam 5

\footnotetext{
${ }^{3}$ En G ${ }^{\text {a }}$ FIGUERAS, 1984: 53.

${ }^{4}$ En MZ. MONTÁVEZ, 1985: 18.

${ }^{5}$ MZ. MONTÁVEZ, 1985: 20; VERNET, 1968: 150; PELLAT, 1970: 195.
} 
A finales del siglo, en 1798, se va a producir un hecho que será considerado como el inicio de una nueva etapa para el mundo árabe: la invasión napoleónica de Egipto. Así éste será el primer país árabe que, tras siglos de aislamiento y languidez, sufra el choque con un Occidente colonial y liberal. A pesar de la corta estancia de los franceses, la huella que deje este primer contacto será importante, provocando en las décadas siguientes reacciones muy diversas.

Napoleón, en su "Proclama" en árabe a los egipcios, justifica su expedición en su amistad hacia el Islam y los otomanos y en su deseo de liberarlos de los injustos gobernantes mamelucos, prometiéndoles libertad e igualdad; pero queda claro desde el principio cuáles eran sus auténticas motivaciones, así como sus amenazas a quien se le enfrentara:

En el nombre de Dios, el Clemente y el Misericordioso. No hay más dios que Dios (...) De parte de la República Francesa, que se basa en los fundamentos de la libertad y la igualdad, el General Bonaparte, Comandante en Jefe de las fuerzas francesas, hace saber a todo el pueblo egipcio que los Sanŷaqs [mamelucos] que han dominado Egipto han tratado a la comunidad francesa con bajeza y desprecio y han perseguido a sus mercaderes con toda clase de extorsiones y violencia. Por tanto la hora del castigo ha llegado (...) ¡Egipcios! Ellos pueden deciros que no he hecho una expedición hasta aquí con otro objetivo que no fuera abolir vuestra religión. Pero eso es pura falsedad y no debéis darles crédito, sino decir a los calumniadores que no he venido hasta vosotros más que con el propósito de rescatar vuestros derechos de las manos del opresor, que sirvo a Dios -alabado y exaltado sea- más que los mamelucos y que venero a su profeta Muhammad y al glorioso Corán. Decidles también que toda la gente es igual a los ojos de Dios y que la única cosa que distingue a unos de otros es la razón, la virtud y el conocimiento. Pero entre los mamelucos ¿qué hay de razón, virtud o conocimiento que pueda distinguirles de otros y cualificarles a ellos solos para poseer todo lo que endulza la vida en este mundo? (...) Si la tierra de Egipto es un feudo de los mamelucos, que muestren el título de propiedad que Dios les confirió (...) Con la ayuda del Altísimo, a partir de este día ningún egipcio será excluido de ocupar posiciones eminentes (...) y así la situación de toda la población será corregida (...) Decid a vuestro pueblo que los franceses también son virtuosos musulmanes y que, confirmando esto, invadieron Roma y destruyeron la Sede del Papa que siempre estaba exhortando a los cristianos a hacer la guerra al Islam (...) Además, los franceses, en todos los tiempos, se han declarado como los mejores amigos del Sultán otomano y enemigos de sus enemigos (...) Y los mamelucos, por el contrario, han retirado su obediencia al sultán y no han seguido sus órdenes. ¡De hecho, nunca han obedecido otra cosa que sus propios apetitos! Bendiciones para los egipcios que actúen en concierto con nosotros (...) o que se queden sentados en sus casas, sin inclinarse por ninguno de los bandos contendientes (...) Pero desgracias para 
aquellos que se unan a los mamelucos y les ayuden en su guerra contra nosotros, pues no hallarán vía de escape y no quedará ni rastro de ellos ${ }^{6}$.

\section{2.- EL SIGLO XIX.}

El historiador egipcio 'Abd al-Rahmmân al-ŶYabartî (m. en 1826), contemporáneo de los hechos napoleónicos y que recoge el texto de esta "Proclama" en su Mudda (1798), clama contra semejante manipulación, explicando la incoherencia de esta "miserable misiva" y acusando a los franceses de falsos, mentirosos, materialistas e incrédulos. Entre otros argumentos, señala que la igualdad es una mentira y una estupidez "pues. Dios ha hecho a unos superiores a otros"17.

Por otro lado, va a dejar constancia tanto de su admiración por la burocracia, la prensa, las bibliotecas y los adelantos científicos de los invasores, como de su rechazo a la libertad y las nuevas costumbres que éstos introducen en su sociedad, reflejando el violento choque de mentalidades que se produce.
A lo largo de este año [1800] lo licencioso comenzó a introducirse en las costumbres indígenas. Las mujeres francesas llegadas con el ejército se paseaban por la ciudad con el rostro descubierto (...), montaban a caballo o en burro (...) y galopaban por las calles riendo y bromeando con los conductores de sus monturas y con los indígenas de clase humilde. Esta libertad indecente les gustó a las mujeres mal educadas de El Cairo y, como los franceses se honraban de su sumisión a las mujeres y les prodigaban regalos y liberalidades, las mujeres empezaron a mantener relaciones con ellos (...) Los franceses se apoderaron de las mujeres y las jóvenes que les gustaron y las hicieron vestir a la manera de su país y adoptar sus costumbres (...) Muchos franceses pedían en matrimonio a las hijas de los notables de El Cairo, y éstos consentían en tal alianza, sea por avaricia, sea por tener protectores en el ejército. Por toda condición los franceses debían hacer las dos profesiones de fe, pero esto no le costaba nada a quien no tenía religión ${ }^{8}$.

Debido a la descomposición y debilitamiento del Imperio Otomano van a surgir movimientos o tendencias autonómicas, especialmente en Egipto y en la Gran Siria. Muhammad 'Alî, que regirá Egipto de 1805 a 1840, creará su propia dinastía hereditaria, la cual gobernará con bastante independencia de la Sublime Puerta. En la Gran Siria se producirán diversos disturbios y revueltas anti-otomanas, así como choques entre drusos y

\footnotetext{
${ }^{6}$ Recogida por al-ŶYabartî. En MOREH, 1975: 40-41.

${ }^{7}$ Cfr. MOREH, 1975: 46.

${ }^{8}$ Fragmento de los ${ }^{c} A \hat{y} \hat{a}$ ib (1805-1821), en VIAL, 1979: 4-5.
} 
maronitas que culminan en la matanza de cristianos de 1860. Por otro lado, se inicia un proceso de instalación colonial: Francia se anexiona Argelia en 1830 y Túnez en 1881; y Gran Bretaña se instala en Egipto en 1882, paradójicamente tras la revuelta nacionalista de 'Urâbî Bâšâ.

La necesidad de adaptarse a las condiciones del mundo moderno provocará un movimiento de renovación lingüística, en que juega un papel esencial el desarrollo de la imprenta y la prensa. La constatación del retraso cultural y tecnológico de Egipto impulsa a Muhammad 'Alî a enviar misiones de estudio a Europa, especialmente a Francia.

Uno de los miembros de la primera expedición, Rifấa all-Tahtâwî (1801-1873), nos dejará en su obra Oro puro para la descripción de París (Tajlîs al-ibrîz ilà taljîs Bârîz, 1834) una deliciosa crónica del impacto que les produce su estancia en este nuevo mundo y sus costumbres tan dispares:

Así nos trajeron varios criados franceses, cuya lengua no conocíamos, y unas cien sillas para sentarse sobre ellas, pues a la gente de este país le extraña que uno se siente sobre una especie de alfombra extendida en el suelo y más aún que se siente en el propio suelo. Luego dispusieron la mesa para el desayuno. Trajeron unas mesas altas, colocaron en fila los platos blancos, como de porcelana persa, y pusieron delante de cada plato un vaso de cristal, un cuchillo, un tenedor y una cuchara, y en cada mesa dos botellas de agua, un recipiente con sal y otro con pimienta. Después colocaron sillas alrededor de la mesa, una para cada uno. Luego trajeron la comida, poniendo en cada mesa uno o dos grandes platos para que uno de los de la mesa sirviera, repartiéndola a todos y dándole a cada uno en su plato algo que éste cortaba con el cuchillo que tenía delante y se lo llevaba a la boca con el tenedor, no con la mano, pues no comen nunca con la mano, ni con el tenedor o el cuchillo de otro, ni beben nunca del vaso de otro, pues pretenden que esto es más limpio y más saludable. Entre los europeos se ve que no comen nunca en platos ni en recipientes de cobre, aunque estén estañados, porque éstos son sólo para cocinar; más aún, siempre usan los esmaltados 9 .

Ante este choque cultural, al-Ṭahtâwî constata las grandes diferencias existentes en todos los campos y el atraso de su país, proponiendo a sus conciudadanos imitar los mejores aspectos de la civilización francesa y europea. Aprecia su régimen político, su industria y su comercio, su cultura, su arte y su ciencia. En otras obras elogiará la libertad civil y la igualdad, base fundamental del progreso. Sus obras para la juventud darán a la nueva generación una instrucción cívica inspirada en principios democráticos. También clamará por la igualdad de sus compatriotas, a pesar de las diferencias de religión, y alabará

${ }^{9}$ Texto árabe en PÉRÈS, 1969: 7. 
la creación de la Cámara de Diputados por el Jedive Ismâcîl (1863-1879) ${ }^{10}$. La obra de al-Ṭahțâî, resistiendo a los prejuicios y a las injusticias, será el manual de los reformadores egipcios de la época.

El tema de la problemática femenina también es abordado por al-Tahtâwî, al constatar el régimen de libertad de la mujer europea, llegando a la conclusión de que la moral femenina no depende del velo o su ausencia, sino de la educación ${ }^{11}$.

Además al-Ṭahtâwî realizará con sus discípulos gran cantidad de traducciones de libros científicos europeos, del Código de Comercio y del Código Civil franceses. Contribuirá así de forma importante a difundir la ciencia europea y a la modernización intelectual de Egipto.

El libanés Ahmmad Fâris al-Šídŷâ (1804-1887) viajará por el Imperio Otomano y Europa, resaltando las diferencias entre sus respectivas sociedades. Escritor de aguda intención social y reformista, incide en los aspectos más problemáticos de la sociedad islámica, entre ellos el de la situación de la mujer. Lo hace en términos muy generalizadores, pero tiene el mérito de aportar una nueva visión en un ambiente en que predomina la creencia en la inferioridad de la mujer, que debe estar sometida al hombre por decreto divino y en virtud de las leyes sociales ${ }^{12}$.

En los países de Europa, la mujer no se casa sino con un hombre que sea de su edad o que le lleve pocos años. Lo que cae fuera de esto se considera como algo anormal y deshonroso. Es como si se desposara un viejo caduco y de buen linaje con un muchacha sin nombre ni rango alguno. Ella se casará entonces para utilizar su nombre y no porque le ame como debe amarse. En los países de Oriente es posible que un hombre se case con una mujer que no tenga ni la mitad de su edad, y en tal hecho no se ve ningún motivo que la empuje a dejarle y abandonarle, porque se piensa que el varón es mejor que la hembra, superior a ella y de mejor linaje. Por ello, él puede encelarla con concubinas, la rebaja en sus derechos y no le tiene un afecto puro. Ni se preocupa de ella cuando sufre si se compadece cuando sirve $\mathrm{s}^{13}$.

El cristiano libanés Butrus al-Bustânî (1819-1883), uno de los grandes patriarcas de la Nahda o renacimiento cultural, va a ser pionero en el tema de la educación femenina. En su Educación de mujeres (Ta lîm al-nisấ' 1849) habla de las ventajas que obtienen los

\footnotetext{
${ }^{10}$ LOUCA, 1970: 60, 62, 63, 69, 70, 71.

${ }^{11}$ VIAL, 1979: 7.

${ }^{12}$ MZ. MONTÁVEZ, 1985: 33-34; VIAL, 1979: 9.

${ }^{13}$ En MZ. MONTÁVEZ, 1985: 34.
} 
niños de la educación de la mujer, ya que la madre vuelca en ellos el conocimiento, cultura y civilización que ella misma tiene ${ }^{14}$.

Por otro lado, al-Bustânî se ve implicado en el conflicto entre drusos y maronitas -cuyas diferencias eran atizadas por los otomanos- que acabaría en la masacre de cristianos de 1860, detenida por la intervención de Francia y la consecución de un régimen especial para el Líbano. Ese año fundará un periódico de dos páginas y escasa duración, El clarín de Siria (Nafîr Sûrîya), en que llamaba a la tolerancia y la cooperación entre las comunidades $^{15}$.

El poeta sirio Adî̉b Ishâaq (1856-1885), también cristiano, es uno de los espíritus "rebeldes" y revolucionarios del pensamiento árabe moderno. Se vió forzado a emigrar a Egipto huyendo de la censura turca, y de ahí tuvo que huir a Francia debido a sus artículos en defensa de la libertad política, de la unidad árabe y en contra de la tiranía otomana ${ }^{16}$. En Francia continuó propagando sus ideas y, viviendo en aquella sociedad, llega a la conclusión de que en la Revolución Francesa reside el principio de la nueva condición de la humanidad, de una vida digna de ser vivida. Por eso grita furioso a sus hermanos:

¡Hombres!, vuestra opresión no tiene ninguna excusa, vuestra resignación es vana, vuestra acción no tiene mérito; pereceréis sin ser llorados. Soportáis la injusticia hasta tal punto que vuestro tirano cree ver en ella un derecho; sonreís a vuestras cadenas como a un ornamento; bajáis tan humildemente la cabeza que se diría al veros: no son hombres, son máquinas dedicadas a trabajar la tierra y a cultivarla para los hombres ${ }^{17}$.

En el norte de África el atraso es aún mayor. Sin embargo, en Argelia surge la imponente figura del emir 'Abd al-Qâdir al-ŶYazâ'irî (1807-1883). Este héroe de la independencia argelina luchará contra Francia con una hábil política de ataques y alianzas en su afán por impedir la conquista de su país, pero al final será vencido por la potencia colonizadora y recluido en Francia. En su cautiverio, este soldado, místico y poeta, representante de los valores típicamente beduinos -tan enraizados en el alma árabe y enfrentados a la civilización urbana-, añorará la libertad del desierto y su modo de vida:

Oh, tú, que excusas a un hombre que ama vivir en las ciudades y criticas al que ama la estepa y el desierto. No censures unas casas ligeras de trasportar

\footnotetext{
${ }^{14}$ HAYWOOD, 1971: 62-63.

${ }^{15}$ HAYWOOD, 1971: 61-62.

${ }^{16}$ MZ. MONTÁVEZ, 1985: 36; GABRIELI, 1971: 250.

${ }^{17}$ Fragmento de al-Durar (1886), en LOUCA, 1970: 129.
} 
ni alabes las casas de barro y piedra.

Si supieras lo que el desierto encierra, me disculparías.

Pero lo ignoras iy cuánto daño hay en la ignorancia! ${ }^{18}$.

\section{3.- LA ETAPA PUENTE AL SIGLO XX.}

Tras la implantación colonial de Occidente en unos países -especialmente en Egipto (1882)- y la lucha de otros por independizarse del Imperio Otomano, el "hecho político" va a cobrar mayor importancia ${ }^{19}$, reflejándose en diversos aspectos de su literatura.

La sociedad siente necesidad de reformas, de nuevos planteamientos. Hay que adecuarse a los nuevos tiempos, hallar fórmulas que permitan al mundo árabe encontrar soluciones válidas a su problemática y situarlo en la nueva realidad. De ahí que, por un lado, se plantee con fuerza la reforma religiosa y doctrinal, y por otro, se busquen nuevas fórmulas políticas que fortalezcan a los países árabes, vertebrándose en torno a dos ejes: el panislamismo y el panarabismo. Todo ello va a reflejarse en una literatura llamada "de polémica", que provocará un intenso y virulento debate de ideas.

Esta literatura de polémica tiene como precursor a un autor tunecino, Jayr al-Dîn alTûnisî (1810-1879), que pretende preservar el mundo islámico de la interferencia europea. Piensa que la única institución capaz de oponerse es el Sultanato Otomano reformado, ejerciendo una especie de "despotismo ilustrado". También propone adoptar los mejores logros de Occidente: libertad, sistema educativo, bibliotecas, transportes, organización comercial... ${ }^{20}$.

Sin embargo, será en Egipto donde esta literatura de polémica adquiera una dimensión más amplia, por su mayor desarrollo científico y cultural. El primer gran reformador será Ŷamâl al-Dîn al-Afgânî (1838-1897). De origen afgano o persa y eterno viajero, su estancia en Egipto será la que marque el punto de partida de todo el movimiento reformista. $\mathrm{Su}$ actividad no será ajena al surgimiento del movimiento nacionalista liderado por ${ }^{\mathrm{C}}$ Urâbî Bâšâ, que culminará en la ocupación británica en $1882^{21}$.

Al-Afgânî es considerado como la fuente de la idea de la unidad árabe y la independencia ${ }^{22}$. Luchador incansable por la libertad y abanderado del anti-colonialismo, cree que la razón de la supremacía de la civilización europea se debe a la reforma de Lutero, que dinamizó las fuerzas sociales y religiosas. Por ello ve necesario fortalecer el

\footnotetext{
${ }^{18}$ Fragmento de Nuzhat al-jâtir (1903); texto árabe en PÉRÈS, 1969: 34-35.

${ }^{19}$ MZ. MONTÁVEZ, 1985: 39.

${ }^{20}$ HAYWOOD, 1971: 116-117.

${ }^{21}$ GOLDZIHER, 1987: 1009.

${ }^{22}$ HAYWOOD, 1971: 118.
} 
mundo islámico mediante una reforma religiosa y una elevación del nivel cultural:

Tenemos que preocuparnos de arrancar algunas inauténticas creencias religiosas y algunos textos legales arraigados en la mentalidad del pueblo y de las clases elevadas, de divulgar el Corán y extender sus auténticas enseñanzas entre la masa, explicándolas tal como son, para que en ellas encuentren lo que pueda hacerles dichosos aquí y en la otra vida. Hay que afinar nuestros saberes y remozar nuestras bibliotecas, componer libros asequibles y de fácil comprensión que nos ayuden a triunfar y a desarrollarnos. (...) Lutero (...) al ver tambalearse a los pueblos de Europa, embrutecidos por su largo sometimiento a los jefes religiosos y a tradiciones irreflexivas y faltas de auténtica fe (...) reformó su moral, enderezóles, purificó sus mentes, y les hizo ver que habían nacido libres. ¿Por qué, pues, habían de someterse a los déspotas? ? $^{23}$.

Sus revolucionarias inquietudes hallarán eco en un nutrido grupo de intelectuales, dentro y fuera de Egipto, que profundizarán en los problemas más acuciantes de la sociedad. El principal discípulo será el šayj Muhammad 'A Abduh (1849-1905), tan íntimamente ligado en un principio a su maestro que es difícil distinguir la autoría de algunas obras. Con él fundó en París la revista El lazo más fuerte (Al-'Urwa al-Wutqaà, 1884), de gran resonancia a pesar de su corta vida.

Más moderado que al-Afgânî, este fundador del modernismo egipcio trata de despertar a su pueblo dando importancia a la moral privada y pública. Propugna una reforma gradual, más que una acción revolucionaria, en la que ocupa el primer lugar la reforma de la educación, especialmente moral y religiosa. Defensor de la libertad, como su maestro, trata de desmontar los prejuicios existentes frente al Islam, dándole una misión liberadora, no fatalista:

El Islam arrancó las raíces de la idolatría (...) Así al hombre se le manifestó su alma libre y generosa, y su voluntad fue liberada de las cadenas que la ataban a la voluntad de otros, fuera una voluntad humana -que se creyera ramificación de la voluntad divina, o la propia voluntad divina, como la de los líderes políticos y religiosos-, fuera de una voluntad fantaseada e inventada por la imaginación -como la creencia en las tumbas, las piedras, los árboles, los astros y cosas similares-, liberándose así su capacidad de decisión de la atadura de los intermediarios, intercesores y adivinos (...) En definitiva, su alma fue liberada de la esclavitud de los estafadores e impostores ${ }^{24}$.

\footnotetext{
${ }^{23}$ MZ. MONTÁVEZ, 1985: 41-42.

${ }^{24}$ Texto árabe en LECOMTE, 1969: 17.
} 
El alejandrino ${ }^{\mathrm{c} A b d}$ Allâh Nadîm (1845-1896), autor de una obra de corte políticosocial, será un nacional-reformista de sólida base religiosa. Intervino en la revuelta de 'Urâbî, y murió en Estambul, como otros muchos defensores de un panislamismo parcialmente desfasado defendido por los otomanos ${ }^{25}$.

Otro discípulo de Afgânî será Qâsim Amîn (1863/5-1908), apóstol de la liberación de la mujer, que luchó especialmente por la supresión del velo. Aunque hoy sus ideas puedan parecernos muy limitadas, su lucha representó un paso decisivo, por lo que fue combatido con vehemencia por sus coetáneos. Ya abordada la necesidad de cambiar la situación de la mujer por algunos pensadores, fue él quien la convirtió en un problema candente, al considerarla como un requisito para el renacimiento árabe.

Vio que la ignorancia de la mujer, su ausencia de la sociedad y su pasividad ante la arbitrariedad y la humillación eran los más horribles defectos que debilitaban la educación nacionalista y la conciencia social. Por medio de la liberación de la mujer pretendía la liberación y la reforma de la sociedad ${ }^{26}$.

Su argumentación por la mejora del status de la mujer egipcia, oriental y musulmana se hace a partir del Islam bien entendido -parece reflejar así las ideas de ${ }^{\mathrm{c}}$ Abduh- ya que muchas malas costumbres no son islámicas, sino herencia de las naciones por las que se propagó el Islam:

Nada en las obligaciones de la religión musulmana ni en los fines que persigue puede ser causa de la decadencia de la mujer musulmana. Todo lo contrario. Esta religión ha procurado a la mujer un lugar elevado en la sociedad ${ }^{27}$.

Su reformismo social empezaba por la reforma de la familia. Así, en su Epístola de la liberación de la mujer (Risâlat tahrîr al-mar'a, 1899), clama:

El hombre no respeta más que la fuerza y no se reprime más que por el miedo; y como la mujer era débil, el hombre oprimió sus derechos, empezó a tratarla con desprecio y abuso, y pisoteó su personalidad.

Es despreciar a la mujer encerrarla en la casa y vanagloriarse de que no salga de ella sino llevada en parihuelas a la tumba.

Es despreciar a la mujer que los hombres declaren que las mujeres no son fiables y leales.

Es despreciar a la mujer ponerle obstáculos para la vida pública y para trabajar en

\footnotetext{
${ }^{25}$ MZ. MONTÁVEZ, 1985: 42-43.

${ }^{26}$ AL-FÂJÛR̂̂, 1986: 104-105.

${ }^{27}$ En WIET, 1966: 276.
} 
cualquier cosa que se relacione con ella ${ }^{28}$.

Qâsim Amîn aboga por un mejor trato a la mujer, que redundará en beneficio de la educación de sus hijos y más tarde en la mejora de la moral pública; aboga por la supresión del velo y del harén, que considera excrecencias no prescritas por el Corán, pues colocan en desventaja a la mujer; aboga porque los maridos les concedan sus derechos; por regular el divorcio y el repudio; o por la educación básica de las niñas, que luego les permitiera ganarse la vida en caso necesario.

A esta lucha también empiezan a sumarse algunas mujeres, como Zaynab Fawwâz (1846-1914), de origen libanés, que sufrió en sus propias carnes el problema en sucesivos matrimonios, por lo que escribiría poemas y artículos para la prensa en defensa de los derechos femeninos, o como las más jóvenes Malak Hifnî Nâșîf (1886-1918), Mayy Ziyâda (1895-1941) y la futura líder del movimiento feminista egipcio Hudà al-Ša ${ }^{c}$ râwî (1882-1947).

La situación irá cambiando en los distintos países árabes, pero el status de la mujer, el velo o la separación de sexos serán considerados con "el último reducto de resistencia" para los varones y, según palabras de un escritor musulmán del momento, "como el último fundamento de nuestra majestuosa estructura social"29.

En el campo del ensayo, la figura más sobresaliente será el modernista liberal Ahmmad Lutfî al-Sayyid (1872-1963). Este gran teorizador del nacionalismo egipcio ejerció una fuerte influencia en las sucesivas generaciones por su acción en el mundo editorial y por la línea que imprimió a la Universidad egipcia que se fundaría en $1908^{30}$.

Otro narrador y ensayista egipcio, Mustafà Lutfî̀ al-Manfalûṭ̂i (1876-1924), influido por ${ }^{\mathrm{C}}$ Abduh, pondrá especial interés en la salud moral. Era un apologista de todo lo musulmán, aun sin rechazar todo lo que ofrecía la civilización occidental. En sus cuentos y ensayos trata una amplia gama de problemas sociales y éticos y fustiga una serie de lacras como el suicidio, el juego o el alcoholismo:

Me dijeron [mis amigos]: "Tu vida está llena de inquietudes e infortunios, que no tienen más cura que la bebida". Dijeron: "La bebida incrementa el bienestar del cuerpo, haciéndolo más vivo. Desata la lengua y enseña al hombre la elocuencia. Da coraje al cobarde, provocando intrepidez y bravura en el corazón". Esto fue lo que oí. Lo creí y fui decepcionado. Creí que en la bebida había cuatro méritos -

\footnotetext{
${ }^{28}$ Texto árabe en PÉRÈS, 1969: 58-59.

${ }^{29}$ Cfr. WIET, 1966: 276-277.

${ }^{30}$ MZ. MONTÁVEZ, 1985: 52.
} 
felicidad, salud, elocuencia y coraje- pero encontré en ella cuatro deméritos pobreza, enfermedad, ruina y locura ${ }^{31}$.

Al-Manfalûtî también trata los problemas del matrimonio, la poligamia, la caridad mal ejercida -proponiendo la creación de sociedades benéficas- la felicidad del pobre, o la ciudad utópica -en que los hombres fueran iguales y tuvieran sus necesidades satisfechas-, con un tono muy conservador, especialmente en el tema de la mujer:

Es cierto que "los hombres son superiores a las mujeres", como dice Dios en su libro sagrado, pero la mujer es también el sostén indispensable para el hombre, el secreto mismo de su vida, desde el grito que lanza al nacer, hasta el gemido que le arranca la muerte ${ }^{32}$.

La región siro-libanesa, que sufre más directamente la tiranía del sultán otomano ${ }^{\mathrm{C}} \mathrm{Abd}$ al-Hamîd, será testigo de la emigración a Egipto y a América de sus intelectuales, ante la atmósfera represiva existente. Y las figuras más importantes realizarán su obra fuera, creando una especie de escuela a la que se llamará "Literatura del Mahŷar".

Dentro de la literatura de polémica en Siria cabe destacar la obra de ${ }^{\mathrm{C}} \mathrm{Abd}$ al-Rahmân al-Kawâkibî (1849-1902), un pionero de las tesis panarabistas que de alguna manera integra con las panislamistas, al propugnar el retorno al Islam auténtico y la primacía árabe en la comunidad islámica:

Los árabes son la gente más a propósito para constituirse en la base de la religión y ejemplo para los musulmanes. Los restantes pueblos siguiéronles al principio y no se avergonzarán ahora de volverlo a hacer ${ }^{33}$.

Al-Kawâkibî dedicaría la mayor parte de su obra a denunciar el despotismo del sultán otomano, capaz de instrumentalizar hasta la religión para sus fines, como se pone de relieve en Caracteres del despotismo (Tabâ'ic al-istibdâd, 1900):

El despotismo es un mal más aniquilador que la peste (...) El despotismo hace pensar las cosas al revés de como son, hasta el punto que algunos césares y reyes pudieron jugar con las religiones en apoyo de su despotismo, y gobiernos se han establecido en servicio suyo. Por el despotismo los hombres han llegado a pensar que quien pide sus derechos es un libertino, y quien los abandona, dócil; un corrupto el que se queja de la injusticia, un ateo el que analiza con inteligencia, y

\footnotetext{
${ }^{31}$ Fragmento de "La primera copa" (Al-ka's al-awwal), de Al-Nazarât (1910), en HAYWOOD, 1971: 156.

${ }^{32}$ En DERMENGHEM, 1979: 347.

${ }^{33}$ MZ. MONTÁVEZ, 1985: 44.
} 
que el pobre hombre es el único ser íntegro y fiel ${ }^{34}$.

Para al-Kawâkibî sólo el conocimiento será capaz de acabar con el despotismo. El déspota no teme las ciencias del lenguaje o de la religión, ya que no disipan el velo de la ignorancia:

Pero el déspota tiembla ante las ciencias de la vida: la sabiduría teórica, la filosofía racional, los derechos de las naciones, la política de la ciudad, la historia detallada, el discurso literario y otras ciencias que desgarran las nubes, hacen aparecer el sol e inflaman los cerebros (...) No cesa la lucha entre el despotismo y la ciencia: los sabios trabajan por extender la ciencia, mientras el déspota intenta apagar su luz (...) Si la ignorancia es disipada, el miedo desaparece y la situación cambia: el déspota se transforma, en contra de su propia naturaleza, en un mandatario honesto temiendo la hora de rendir cuentas; en un jefe justo que teme la revancha (...) El miedo del déspota viene de su conocimiento, mientras que el miedo de sus súbditos procede de su ignorancia (...) El Islam, e incluso todas las religiones, está fundado sobre el hecho de que no hay otro dios que Dios; es decir, que no debe ser adorado nadie más que él, el Creador Supremo. Si adoración significa humillación y sumisión, el significado del versículo "No hay más dios que Dios" es que no hay que humillarse ni someterse más que a Dios. ¿Cómo podrían tolerar los déspotas que sus súbditos conocieran este significado y actuaran de acuerdo con él ? $^{35}$.

En el campo de la poesía egipcia, que en este período alcanza la cúspide del neoclasicismo, también hallamos la defensa de tesis panislamistas y panarabistas, aunque en su mayor parte se trate de un nacionalismo egipcio. Las obras de tres grandes poetas Šawqî, Hâfiz Ibrâhîm y Mutrân- tocarán todos los campos de la política, la economía y la sociedad, y la historia del Egipto de su tiempo podrá seguirse a través de sus poemas.

Ahmad Šawqî (1868-1932) será turcófilo hasta la primera guerra mundial. Recordando los sucesos de "Dinsiwa" (Dinšaway), canta a aquellos que lucharon contra la ocupación británica:

¡Dinsiwa, por sobre tus colinas a la paz!

Los días se han llevado tu reposo.

Los mártires de tus ideas por el país se separaron,

lejos como un viento del norte se esparcieron (...)

¿Cómo han quedado en ti las viudas, sin sus hombres?

y ¿en qué estado los huérfanos?

\footnotetext{
34: MZ. MONTÁVEZ, 1985: 43-44.

${ }^{35}$ En ABDEL MALEK, 1965: 67-68.
} 
Tu veintena de casas está deshabitada.

Después de la alegría, les ha llegado la soledad y las sombras (...)

¡Ah, Nerón, si hubieras alcanzado la época de Cromer, sabrías en qué forma perdióse la razón! ${ }^{36}$.

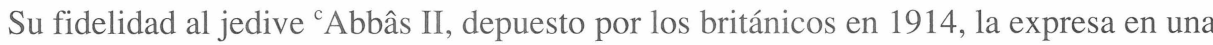
oda que le proporcionó mucha popularidad:

¿Traicionaré a Ismâĉ̂l y a sus hijos cuando me he criado a los pies de Ismâcîll? ${ }^{37}$.

Los ingleses le obligaron a exiliarse, y pasó la guerra en España, en Barcelona. Al finalizar la contienda, Šawqî resucita, y decide curar sus heridas contemplando los monumentos árabes de Andalucía, que luego describirá majestuosamente en El Viaje a alAndalus (Rihla ilà-l-Andalus, 1939). Al regresar a Egipto en 1920 seguirá una línea de nacionalismo egipcio.

Si Šawqî fue el más destacado, Hâfiz Ibrâhîm (1871-1932) entronca mejor con el sentimiento del pueblo egipcio por su preocupación por las gentes humildes. Por ejemplo, en el poema sobre las pirámides destaca el dolor de los miles de hombres anónimos que, tiranizados, las levantaron y no la gloria del poderoso monarca que las mandó construir ${ }^{38}$. Expresó en verso su admiración hacia el califato, pero tras conocer a ${ }^{\mathrm{c} A b d u h}$ se tornó hacia el nacionalısmo egipcio. En el poema "Queja de Egipto contra la ocupación" (Šakwà Mișr mina-l-ihtilâl), dirigida al primer ministro británico, muestra sus preferencias por los días del jedive Ismâĉ̂l. En otro poema, sobre el incidente de caza de Dinšaway que desató una fuerte represalia sobre los campesinos, se dirige irónicamente a los ingleses:

Oh, tú, que diriges nuestro asuntos, ¿has olvidado nuestra lealtad y afecto?

Reduce tus ejércitos, duerme profundamente, busca tu juego en cada rincón de la tierra.

Es posible que falten en la colina palomas anilladas, seguramente hay hombres suficientes para que les dispares.

Nosotros y las palomas torcaces somos iguales, pues las anillas aún siguen en nuestros cuellos ${ }^{39}$.

\footnotetext{
${ }^{36}$ MZ. MONTÁVEZ, 1958: 82.

${ }^{37}$ VERNET, 1968: 186.

${ }^{38}$ MZ. MONTÁVEZ, 1985: 49.

${ }^{39}$ En BADAWI, 1975: 46.
} 
El poeta libanés Jalîl Muțrân (1870/72-1949) tuvo que huir de su tierra al caer en desgracia ante las autoridades otomanas. Tras una corta estancia en París se instala definitivamente en Egipto, país que en aquellos momentos ofrecía una mayor libertad de expresión. Aunque al principio se cuidó de no mostrar hostilidad hacia la ocupación británica, colaboró con el líder nacionalista Mustafà Kâmil y el partido Nacionalista. Dedicado al periodismo, denunciará la limitación a la libertad de prensa que impuso en Egipto Sir Eldon Gorst en 1909:

¡Dispersa a sus mejores hombres por tierra y mar!

¡Mata a sus hombres libres uno por uno!.

El bien seguirá siendo bien hasta el fin de los tiempos,

y el mal seguirá siendo mal.

Quiebra todas la plumas ¿evitará eso

que las manos graben la piedra?

Corta las manos ¿impedirá eso

que los ojos miren con ira?

Arranca los ojos, ¿prevalecerá eso

contra el aliento colérico?

Detén, pues, el aliento, ya que sería eso

lo máximo que podrías hacernos.

Entonces nos libraríamos de ti,

y te daríamos las gracias por ello ${ }^{40}$.

Su defensa de la libertad también le llevará a denunciar la tiranía, como lo hace en "La ejecución de Buzarŷumuhr" (Maqtal Buzarŷumuhr) -donde sólo una mujer, la hija del visir al que van a ejecutar, es capaz de denunciar a Cosroes-, en "Las pirámides" (Al-ahrâm) -en que no deja de atacar el despotismo de los faraones- o en "Nerón" (Nîrûn), con todo su contenido de autocrítica:

Ese pueblo que le dió la victoria

es más merecedor de vergüenza que Nerón.

¿Qué era Nerón, al que adoraban?

Era un ser rudo e inexperto

un enano al que encumbraron.

Se arrodillaron ante él y se hizo arrogante.

Le glorificaron, y extendió su sombra,

llenando los horizontes de crímenes.

Le cedieron su fuerza, y así

se convirtió en un tirano o algo peor.

${ }^{40}$ En BADAWI, 1975: 80-81. 
El gobernante oprime sólo cuando no teme

la violencia de quienes le han dado poder.

Hay quien denuncia a Nerón, pero yo denuncio a la nación:

si le hubiera rechazado, se habría retirado.

Cada pueblo crea su "Nerón",

se le llame César o Cosroes ${ }^{41}$.

En Iraq, también surge la necesidad del cambio y la lucha contra el despotismo de ${ }^{\mathrm{c} A b d}$ al-Hamîd. Ŷamîll Șidqî all-Zahâwî (1863-1936), gran divulgador de la ciencia moderna, combatirá la tiranía política y los prejuicios sociales. Defensor de los derechos de la mujer y contrario al velo y la poligamia, tras la publicación del artículo "La mujer y su defensa" (Al-mar'a wa-l-difấc can-hâ, 1908), sufriría la hostilidad de sus compatriotas. Su encendida temática política y su hiriente denuncia de las desigualdades y las injusticias sociales constituirán características de la poesía iraquí a partir de entonces ${ }^{42}$.

Su largo poema Revolución en los infiernos (Tawra fî-l-ŷhahim, 1929) causó un gran revuelo al atacar las concepciones religiosas tradicionales y los fundamentos de la religión, aunque también encubre una llamada a la revuelta contra el régimen feudal: al morir el poeta, se le niega la entrada al paraíso, donde sólo hay seres mediocres; al llegar al infierno, se consuela pensando que los únicos que lo habitan son los seres más inteligentes y dotados de todos los tiempos: Sócrates, Platón, Aristóteles, Dante, Shakespeare, Copérnico, Newton, Voltaire, Rousseau, Darwin y Spencer o Imru'-1-Qays, Omar Jayyam, Abû Nûwâs, al-Mutanabbî, al-Kindî, Avicena, Averroes y al-Ma ${ }^{c}$ arrî; descontentos con su suerte, éstos se rebelan con la ayuda de los demonios y son conducidos a la victoria por al-Mac $\operatorname{arrî}^{43}$.

De su deseo de acabar con el oscurantismo y la tiranía dan testimonio su poema "Al tirano" (Ilà-l-tâgiya) -en que clama por un poco de justicia para el sufrido pueblo mantenido en la ignorancia- o sus palabras dirigidas "A su esposa":

Oh, Butayna, si el enemigo acerca la hora de mi muerte con un revólver que descarga o con un golpe de sable, muéstrate firme en la desgracia e imagínate que me reuno contigo en los sueños (...)

No seré el primero en perecer por su pueblo, esperando su progreso con los otros pueblos, no aceptando el oscurantismo, y no cesando

\footnotetext{
${ }^{41}$ Texto árabe en KHOURI-ALGAR, 1974: 42.

${ }^{42}$ MZ. MONTÁVEZ, 1985: 51.

${ }^{43}$ Cfr. BADAWI, 1975: 54.
} 
de trabajar por salvarlo de los prejuicios.

Yo deseo la vida para ellos, y ellos quieren mi muerte.

¡Qué diferencia entre mi deseo y el suyo! $!^{44}$.

\section{4.- CONCLUSIÓN.}

Por todo lo expuesto podemos llegar a las siguientes conclusiones:

- En el siglo XVIII la atención se centra en el rechazo a la tiranía por parte del pueblo sometido, la crítica a las instituciones culturales, la necesidad de reformar el Islam, volviendo a sus bases primitivas, y la constatación de las maniobras europeas en su intento de dominarles.

- En el siglo XIX, tras el choque con la cultura de Occidente, se constata el atraso cultural y tecnológico, así como el aislamiento en que el mundo árabe vivía; ese choque produce algunos rechazos a un sistema de libertad e igualdad para ellos desconocido, pero también el asombro ante sus costumbres y la admiración por sus adelantos técnicos, su cultura, su ciencia y sus instituciones fundadas en los principios de la Revolución Francesa; la opresión y el servilismo serán duramente denunciados; se valorarán las raíces beduinas del alma árabe en contraste con la vida urbana moderna; el tema de la marginación de la mujer, su educación y su moral empieza a destacar, al compararse con la situación femenina en Europa; y también se hacen llamadas a la tolerancia y cooperación intercomunitarias en el Líbano tras las masacres de 1860.

- Desde el último tercio del siglo XIX hasta la primera guerra mundial, es decir, en la etapa puente, la literatura de polémica será la que más se ocupe de la necesidad de reformas: por un lado, la reforma religiosa, para adaptar el Islam a las nuevas condiciones, volviendo a las creencias auténticas; por otro, la reforma política, la necesidad de reforzar a los países árabes frente a Occidente; las primeras propuestas del panislamismo irán siendo superadas por la idea de unidad panárabe. Como soluciones a la conflictiva situación se propone adoptar los logros de Occidente; la reforma de la enseñanza, con la erradicación de la ignorancia y la superstición; el cambio del status de la mujer -reconocimiento de sus derechos, supresión del velo, regulación de la poligamia, el repudio y el divorcio, supresión de las barreras que la separan del resto de la sociedad-; la reforma ética y moral; y la reforma social que elimine las lacras de la injusticia, la miseria y la enfermedad; pero el tema dominante será el de la denuncia de la tiranía y el despotismo -sea otomano, occidental o de los propios dirigentes nativos- y la búsqueda de la libertad y la

\footnotetext{
${ }^{44}$ En DERMENGHEM, 1979: 371; texto árabe en PÉRÈS, 1969: 106-107.
} 
independencia que tanto les costará conseguir.

BIBLIOGRAFÍA.

- ABDEL MALEK, Anouar

$1965 \quad$ Anthologie de la littérature arabe contemporaine. Les essais. Ed. du Seuil. París.

- BADAWI, M.M.

1975 A Critical Introduction to Modern Arabic Poetry. Cambridge University Press. Cambridge.

- DERMENGHEM, Émile

1979 Les plus beaux textes arabes. Ed. D’Aujourd'hui. París.

- AL-FÂJÛR̂̂, Hannâ

$1986 \quad A l-\hat{y} a m^{c} i^{i}$ fì $^{\prime} a^{\prime} r \hat{j} j$ al-adab al-carabî. Al-adab al-hadît. Dâr al-Ŷ̂îl. Beirut.

- GABRIELI, Francesco

$1971 \quad$ La literatura árabe. Ed. Losada. Buenos Aires.

- G ${ }^{\mathrm{a}}$ FIGUERAS, Tomás

1984 (1934) Cuentos de Yehá. Padilla Libros. Sevilla.

- GOLDZIHER, I.

1987 "Djamal al-Dîn al-Afghânî", en First Encyclopaedia of Islam. (19131936). E. J. Brill. Leiden. Vol. II, pp. 1008-1011.

- HAYWOOD, John A.

1971 Modern Arabic Literature (1880-1970). An Introduction with Extracts in Translation. Lund Humphries. Londres.

- KHOURI, Mounah A.

1974 y H. ALGAR. An Anthology of Modern Arabic Poetry. University of California Press. Berkeley-Los Ángeles-Londres.

- LECOMTE, Gérard

1969 Textes littéraires arabes des XIX et XX siècles, choisis et commentés. E. Klincksieck. París.

- LOUCA, Anouar

$1970 \quad$ Voyageurs et écrivains égyptiens en France au XXe siècle. Didier. París.

- MZ. MONTÁVEZ, Pedro

$1958 \quad$ Poesía árabe contemporánea. Escélicer. Madrid.

1985 Introducción a la literatura árabe moderna. CantArabia. Madrid.

- MOREH, S.

1975

Al-Jabarti's Chronicle of the First Seven Months of the French Occupation of Egypt. E. J. Brill. Leiden. 
- PELLAT, Charles

$1970 \quad$ Langue et littérature arabe. Armand Colin. París.

- PÉRÈS, Henri

1969 (1959) La littérature arabe et l'Islam par les textes. Les XIX et XX siècles. Adrien Maisonneuve. París.

- VERNET, Juan

$1968 \quad$ Literatura árabe. Ed. Labor. Barcelona.

- VIAL, Charles

$1979 \quad$ Le personnage de la femme dans le roman et la nouvelle en Égypte de 1914 a 1960. Institut Français. Damasco.

- WIET, Gaston

1966 Introduction a la littérature arabe. Mainsonneuve et Larose. París. 
